This item was submitted to Loughborough's Research Repository by the author.

Items in Figshare are protected by copyright, with all rights reserved, unless otherwise indicated.

\title{
Flexural behaviour of AR-glass textile reinforced 3D printed concrete beams
}

PLEASE CITE THE PUBLISHED VERSION

https://doi.org/10.1007/978-3-030-49916-7_73

PUBLISHER

Springer

VERSION

AM (Accepted Manuscript)

PUBLISHER STATEMENT

The final authenticated version is available online at https://doi.org/10.1007/978-3-030-49916-7_73.

LICENCE

CC BY-NC-ND 4.0

\section{REPOSITORY RECORD}

Wang, David, Nikolaos Konstantinidis, Simon Austin, Richard Buswell, Sergio Cavalaro, and Domenico Cecinia. 2020. "Flexural Behaviour of Ar-glass Textile Reinforced 3D Printed Concrete Beams". Loughborough University. https://hdl.handle.net/2134/12196068.v1. 


\title{
Flexural Behaviour of AR-glass Textile Reinforced 3D Printed Concrete Beams
}

\author{
Weiqiang Wang, , , Nikolaos Konstantinidis ${ }^{2, *}$, Simon A. Austin ${ }^{1}$, Richard A. Bus- \\ well $^{1}$, Sergio Cavalaro ${ }^{1}$, and Domenico Cecinia ${ }^{2}$ \\ ${ }^{1}$ School of Architecture, Building and Civil Engineering, Loughborough University, Lough- \\ borough LE11 3TT, UK \\ ${ }^{2}$ Concrenetics BVBA, Parc Industriel de Tournai Ouest 2-16, rue des Sablières, 7503 Tournai, \\ Belgium \\ W.Wang@lboro.ac.uk; nikos@concrenetics.com
}

*Author contributions: Weiqiang Wang and Nikolaos Konstantinidis contributed equally.

\begin{abstract}
D concrete printing (3DCP) enables automation of construction manufacturing through digital design and workflow, adding value through high degrees of form freedom. The process constraints during the printing, however, hamper the application of reinforcement and hence limit the ductile behaviour that is achievable in 3D printed concrete structures. Although a number of reinforcement strategies have been developed and these strategies can to some extent address these limitations, the reinforcement challenges of 3D printed concrete structures are not satisfactorily addressed yet. This paper proposes another reinforcement strategy of incorporating alkali-resistant (AR)-glass textile between the printed concrete layers. To validate the strategy, small-scale printed concrete beam specimens reinforced with one to three layers of textiles were tested under three-point bending. The results were compared to those obtained from equivalent 'cast' specimens. Comparable flexural behaviours were observed between the cast and printed textile reinforced concrete (TRC) specimens. Moreover, the flexural behaviours of printed specimens exhibited lower scatter than the flexural behaviours of cast specimens, which was probably due to the precise digitally controlled printing process. Future research should focus on the application of textile reinforcement in more complex 3D printed concrete structures.
\end{abstract}

Keywords: 3D Concrete Printing, Reinforcement, AR-glass Textile, Flexural Behaviour.

\section{Introduction}

3D concrete printing (3DCP) is an extrusion-based additive manufacturing technique in which the concrete layers are deposited on top of each other to gradually form objects without the need of formwork. As a disruptive technique, 3DCP is attracting significant attention worldwide [1,2]. Despite the many advantages of 3DCP, its ap- 
plication is still limited by the difficulty of incorporating reinforcement to obtain the desired strength and post-cracking ductility [3]. In order to address this limitation, a number of reinforcement strategies have been proposed, including: printable fibre reinforced concrete; external reinforcement arrangements; 3D printed formworks; incorporation of high strength steel wires into the concrete beads during printing; concrete printing around fixed steel reinforcement; and parallel multi-arm printing of concrete and reinforcement $[3,4]$. Although these strategies can to some extent address the limitations of 3D printed concrete structures, sufficient reinforcement of 3D printed complex geometry (e.g. doubly curved) concrete structures remains a challenge [5].

In recent years, the application of textile reinforced concrete (TRC) in construction industry has received much attention [6,7]. Textile reinforcements are usually made of materials such as carbon, basalt, and glass fibres that can meet the growing durability and lightweight requirements for the concrete structures [7]. Moreover, TRC is of high formability compared to steel reinforced concrete [6, 7]. Therefore, TRC is particularly competitive for complex thin-shell structural elements with a fine grain concrete matrix $[6,7]$.

Given the potential of TRC, alkali-resistant (AR) glass textile reinforcement was chosen in this study to investigate the structural potential of textile reinforced 3D printed concrete. Twenty-one TRC specimens were manufactured to examine the influences of manufacturing method (cast and printed) and textile layers (one to three layers) on the flexural performance of TRC specimens.

\section{Experimental program}

\subsection{Specimen design}

In total 21 specimens, including 12 cast and 9 printed, were prepared and tested under three-point loading (Table 1). The specimens were $450 \mathrm{~mm}$ in length, $100 \mathrm{~mm}$ in width and $20 \mathrm{~mm}$ in depth. The span length was $400 \mathrm{~mm}$. A varying layer of textiles (one to three layers) were placed into the concrete beams with $5 \mathrm{~mm}$ spacing between neighbouring layers, positioned as shown in Fig. 1. The concrete cover thicknesses were $5 \mathrm{~mm}$ for all specimens. Four nominally identical specimens were manufactured for the cast specimens, while three nominally identical specimens were manufactured for the printed specimens. The labelling of each specimen is named as follows: (1) " $C$ " and "P" indicate the cast and printed specimens, respectively; (2) "L" and the number afterwards indicate the textile layers; and (3) the last number "1", "2" , "3", and " 4 " to differentiate between the nominally identical specimens. 
Table 1. Details of test specimens.

\begin{tabular}{lccccc}
\hline Specimen & $\begin{array}{c}\text { Length } \\
(\mathrm{mm})\end{array}$ & $\begin{array}{c}\text { Span } \\
(\mathrm{mm})\end{array}$ & $\begin{array}{c}\text { Width } \\
(\mathrm{mm})\end{array}$ & $\begin{array}{c}\text { Depth } \\
(\mathrm{mm})\end{array}$ & $\begin{array}{c}\text { Number of } \\
\text { textiles }\end{array}$ \\
\hline C-L1-1, 2, 3, 4 & 450 & 450.0 & 100.0 & 20.0 & 1 \\
C-L2-1, 2, 3, 4 & 450 & 450.0 & 100.0 & 20.0 & 2 \\
C-L3-1, 2, 3, 4 & 450 & 450.0 & 100.0 & 20.0 & 3 \\
P-L1-1, 2, 3 & 450 & 450.0 & 100.0 & 20.0 & 1 \\
P-L2-1, 2, 3 & 450 & 450.0 & 100.0 & 20.0 & 2 \\
P-L3-1, 2, 3 & 450 & 450.0 & 100.0 & 20.0 & 3 \\
\hline
\end{tabular}

Note: The actual specimen sizes varied due to the placement of textiles and manufacturing errors.

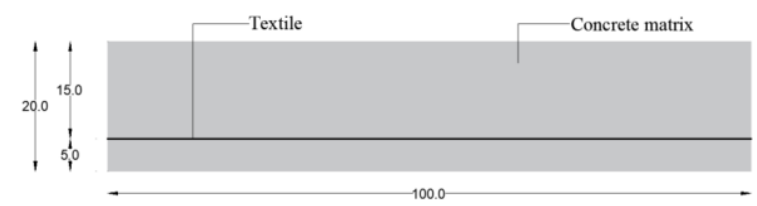

(a) One layer of textile

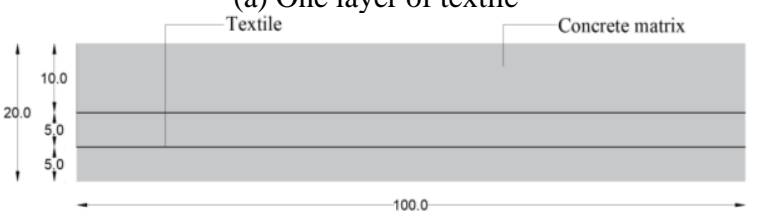

(b) Two layers of textiles

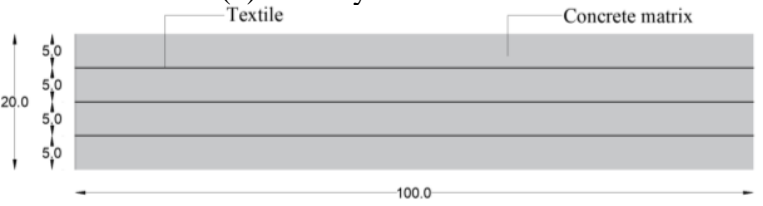

(c) Three layers of textiles

Fig. 1. Specimen details (Units in $\mathrm{mm}$ )

\subsection{Materials}

The mix proportions of concrete are provided in Table 2 with a target compressive strength of $100 \mathrm{MPa}$ after 28 days. During the mixing process, the dry components were mixed with water and a polycarboxylate based superplasticizer to lower the water/binder ratio and hence increase the workability and strength. A retarder, formed by amino tris (methylene phosphonic acid), citric acid and formaldehyde, maintained enough open time, facilitating a constant flow during printing [8]. The concrete also contained $12 / 0.18 \mathrm{~mm}$ length/diameter polypropylene microfibers to reduce the possibility of plastic shrinkage. The compressive strength of the cast concrete was determined by following the BS EN 12390-3:2009 [9]. Based on the test results, the concrete compressive strength measured with $100 \mathrm{~mm}$ cubes was $102 \mathrm{MPa}$ at 28 days with a coefficient of variation of 0.057 . 
Table 2. Mix proportions of concrete

\begin{tabular}{lc}
\hline Constituents & Quantity $\left(\mathrm{kg} / \mathrm{m}^{3}\right)$ \\
\hline Sand & 1244 \\
Cement 52.5 & 581 \\
PFA & 166 \\
Silica fume & 83 \\
Water & 212 \\
Retarder Delvo & 4.2 \\
Spa Glenium 51 & 8.3 \\
PP Fibers & 1.2 \\
\hline
\end{tabular}

Alkali-resistant (AR)-glass fibre textile was used as the reinforcement, which was provided by the Institute for Textile Technology (ITA) of Aachen University (RWTH), Germany. The textile had the warp yarns with $8 \mathrm{~mm}$ spacing and weft yarns with $8 \mathrm{~mm}$ spacing. The reinforcing area per $100 \mathrm{~mm}$ width was $16.12 \mathrm{~mm}^{2}$. The tensile elastic modulus and the tensile strength of the textile (in both directions) were $70 \mathrm{GPa}$ and $1800 \mathrm{MPa}$, respectively [7].

\subsection{Experimental preparations and instrumentations}

For both cast and printed specimens, concrete panels were prepared and later the required specimens were cut from these panels.

For the cast specimens, the concrete was cast into a specially designed wooden formwork. Before the casting, the formwork was greased inside to ensure a smooth bottom surface and easy demoulding. First, a thin layer $(5 \mathrm{~mm})$ of concrete was placed into the formwork and a trowel was used to smooth the concrete surface. Afterwards, the first layer of epoxy-coated textile was placed manually onto the concrete and a lamination roller was used to ensure the textile was evenly distributed and integrated well within the concrete. It is noted that a preliminary study conducted by the authors suggested that the epoxy-coated textile exhibits higher reinforcement efficiency than the non-coated textile. The above process was repeated until the final layer of concrete was placed and evenly finished.

After casting, the concrete panel surface was covered with plastic sheet to prevent moisture loss and impairment of the hydration of the cement, which was essential to alleviate the adverse influence of plastic and drying shrinkage cracks. The cast concrete panels were left to cure for the first 24 hours and then demoulded and cured in a $20{ }^{\circ} \mathrm{C}$ water tank until the testing date. Finally, the concrete panels were cut into 100 $\mathrm{mm}$ wide specimens with a diamond saw.

A $15 \mathrm{~mm}$ diameter nozzle was used for the printing and the depth of each concrete layer was $5 \mathrm{~mm}$. After the bottom layer of concrete was printed, the first layer of textile was placed manually onto the printed concrete and then the second layer printed. This process was repeated until the last layer of concrete was printed. During the 
printing, all the extrusion beads were printed in one orientation, consistent with the warp direction of the textile. For both cast and printed specimens, each textile reinforcement layer contained ten yarns in the warp direction, which resulted in the reinforcement ratios (by volume) of $0.81 \%, 1.61 \%$ and $2.42 \%$, respectively, for one layer, two layers and three layers textile reinforced concrete (TRC) specimens (in the warp direction). The specimens were subjected to three-point loading in a $100 \mathrm{kN}$ Instron screw-driven machine. The tests were under central deflection control for the first 4 $\mathrm{mm}$ of deflection at a rate of $0.5 \mathrm{~mm} / \mathrm{min}$ and then by the crosshead displacement set at $1 \mathrm{~mm} / \mathrm{min}$.

\section{Experimental results}

\subsection{Specimen depth}

The specimens' depth was measured before the tests in three locations (Table 3 and Fig. 2). The specimen depth continuously increases by placing more layers of textiles into the printed TRC specimens. Nevertheless, the depth changes for cast TRC specimens do not follow the same trend. Surprisingly, the cast TRC specimens with two layers of textiles achieve the largest depth, followed by the cast TRC specimens with three layers and one layer of textiles. However, the designed depth $(20 \mathrm{~mm})$ is very small and the manufacturing error can be large for the cast TRC specimens.

Table 3. Average depths of the specimens (unit in $\mathrm{mm}$ )

\begin{tabular}{lccc}
\hline Method & One layer & Two layers & Three layers \\
\hline Cast & 21.3 & 23.3 & 21.6 \\
Printed & 20.9 & 21.7 & 21.8 \\
\hline
\end{tabular}

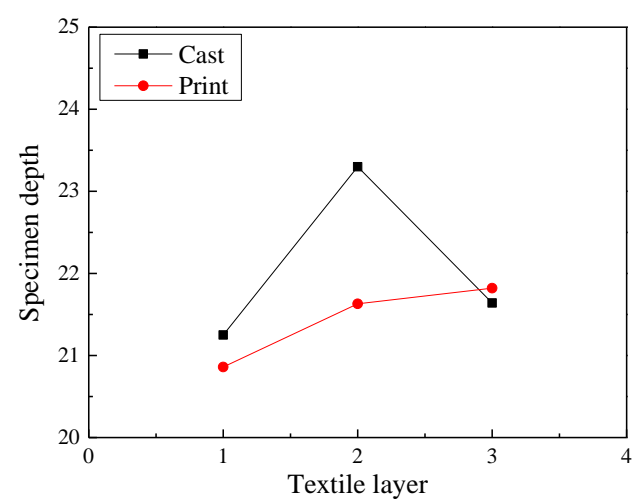

Fig. 2. Influence of textile layers on the specimen depth. 


\subsection{Failure modes}

Fig. 3 shows the representative failure modes of the TRC specimens. Regardless of concrete types (cast and printed), most specimens exhibit a similar failure mode, that is, flexural failure after the ultimate tensile strain of the bottom layer of textile is reached (Fig. 3a). One printed specimen (P-L3-2) and one cast specimen (C-L2-1) exhibit combined flexural and shear-delamination failure, as illustrated in Fig. 3b. This combined failure mode is due to the debonding between the bottom textile and the concrete. Fig. 4 shows the representative localized failure patterns. During the tests, cracks first occurred at the tension side and then began to propagate towards the compression side in the mid-span region, as shown in Fig. 4a. With the increase of flexural load, wider cracks occur throughout the specimen width in the tension side (Fig. 4b), and severe concrete crushing in the compression side (Fig. 4c). Moreover, due to the superior adhesive bond between textile and concrete, most TRC specimens exhibited the desired flexural failure with large deflections.

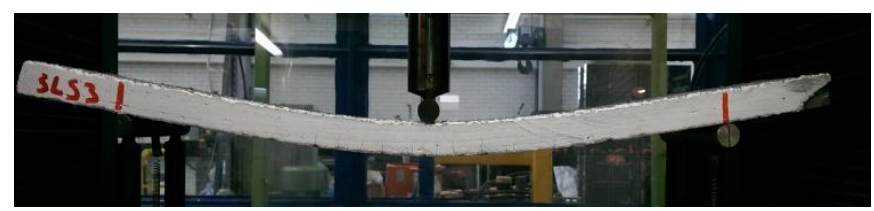

(a) Flexural failure

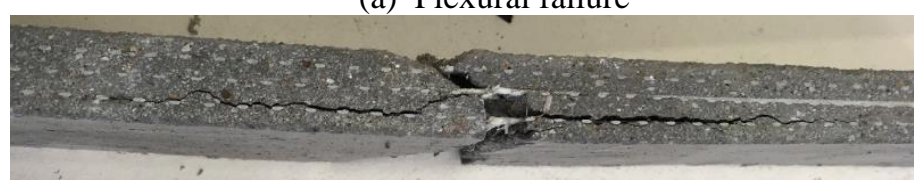

(b) Combined flexural and shear-delamination failure

Fig. 3. Representative failure modes.

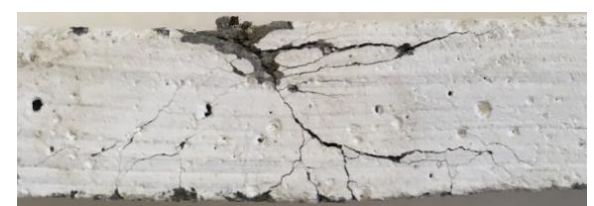

(a) Crack propagations along the depth

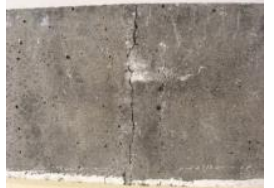

(b) Cracks in the tension side

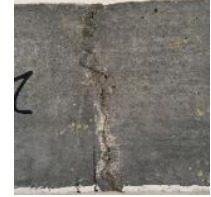

(c) Crushing in the compression side

Fig. 4. Representative localized failure patterns 


\subsection{Nominal flexural stress-strain behaviours}

The detailed test data, including the peak flexural load $P$, nominal flexural strength $f$ and the nominal flexural strain $\varepsilon$ at $f$, are summarized in Table 4. In this section, the nominal flexural stress and nominal flexural strain are calculated according to the Euler-Bernoulli theory for each specimen by considering the actual specimen size. The nominal flexural stress-strain responses for the cast and printed TRC specimens are shown in Fig. 5 and Fig. 6, respectively. Typical bi-linear flexural stress-strain curves are observed for all the TRC specimens. The curves exhibit two stages.

In the first stage, a linear elastic response occurs until the first cracking of concrete. At this stage, the contribution from the textile to resist the flexural load is insignificant since the flexural deflection of the specimen is very small and thus the tensile contribution from the textile is negligible. Therefore, the flexural stiffnesses at this initial stage are almost identical for the specimens with different layers of textiles. In the second stage, the specimens experience multiple tensile cracking as well as concrete crushing that leads to a decrease in flexural stiffness.

Table 4. Summary of the flexural test results.

\begin{tabular}{lcccccc}
\hline Specimen & $P(\mathrm{~N})$ & $P_{\text {ave }}(\mathrm{N})$ & $f(\mathrm{MPa})$ & $f_{\text {ave }}(\mathrm{MPa})$ & $\varepsilon(\%)$ & $\varepsilon_{\text {ave }}(\%)$ \\
\hline C-L1-1 & 2477.4 & & 32.1 & & 1.79 & \\
C-L1-2 & 2482.2 & 2454.8 & 32.2 & 31.9 & 1.63 & 1.68 \\
C-L1-3 & 2213.2 & $(0.07)$ & 28.7 & $(0.07)$ & 1.63 & $(0.05)$ \\
C-L1-4 & 2646.4 & & 34.3 & & 1.67 & \\
\hline C-L2-1 & 3877.2 & & 42.1 & & 1.85 & \\
C-L2-2 & 3691.2 & 3752.3 & 40.1 & 40.8 & 1.71 & 1.71 \\
C-L2-3 & 3529.2 & $(0.05)$ & 38.3 & $(0.05)$ & 1.51 & $(0.08)$ \\
C-L2-4 & 3911.5 & & 42.5 & & 1.77 & \\
\hline C-L3-1 & 3040.0 & & 41.4 & & 1.69 & \\
C-L3-2 & 3196.4 & \multirow{2}{*}{3171.2} & 43.5 & 42.1 & 1.72 & 1.74 \\
C-L3-3 & 3191.9 & $(0.03)$ & 43.4 & $(0.04)$ & 1.78 & $(0.02)$ \\
C-L3-4 & 3256.5 & & 40.3 & & 1.77 & \\
\hline P-L1-1 & 1976.7 & \multirow{2}{*}{2044.1} & 29.6 & 30.6 & 1.63 & \multirow{2}{*}{1.70} \\
P-L1-2 & 2160.7 & $(0.05)$ & 32.4 & $(0.05)$ & 1.81 & $(0.06)$ \\
P-L1-3 & 1995.0 & & 29.9 & & \\
\hline P-L2-1 & 2611.9 & \multirow{2}{*}{2760.6} & 39.2 & 41.4 & 1.76 & \multirow{2}{*}{1.84} \\
P-L2-2 & 2739.9 & $(0.06)$ & 41.1 & $(0.06)$ & 1.83 & $(0.05)$ \\
P-L2-3 & 2929.9 & & 43.9 & & \\
\hline P-L3-1 & 2654.1 & \multirow{2}{*}{2822.0} & 39.8 & 42.3 & 1.49 & \multirow{2}{*}{1.68} \\
P-L3-2 & 2849.1 & $(0.06)$ & 42.7 & $(0.05)$ & 1.74 & $(0.10)$ \\
P-L3-3 & 2962.8 & & 44.3 & & 1.82 & \\
\hline
\end{tabular}

Note: $P$ indicates the flexural load; $P$ ave indicates the average flexural load; $f$ indicates the nominal flexural strength; $f_{\text {ave }}$ indicates the nominal flexural strength; $\varepsilon$ indicates the nominal flexural strain at $f$; and $\varepsilon_{a v e}$ indicates the average nominal flexural strain at $f$. Coefficient of variations $(\mathrm{CoVs})$ are calculated as included in the brackets. 
The flexural performance of cast and printed specimens can be enhanced by increasing the layers of textiles, and the improvement between one layer and two layers is significant, but smaller between two and three layers. This difference is due to the location of each layer: at the rupture of the bottom layer, the tensile capacities of the middle and top layers are not fully utilized.

The flexural behaviour of the cast TRC specimens is more variable than their $3 \mathrm{D}$ printed counterparts (Table 4 and Figs. 5 and 6). One possible reason is that the textile positions and concrete layer thicknesses of cast specimens vary more than the uniformly printed counterparts, due to the method of securing each layer of textile at the sides of the moulds. As shown in Fig. 2, the thickness of the 2-layer cast specimen depth was significantly higher than the printed counterpart.

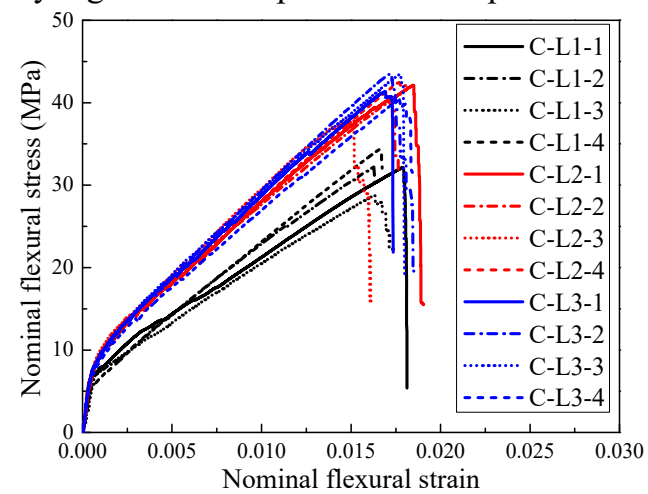

Fig. 5. Flexural behaviour of cast TRC specimens.

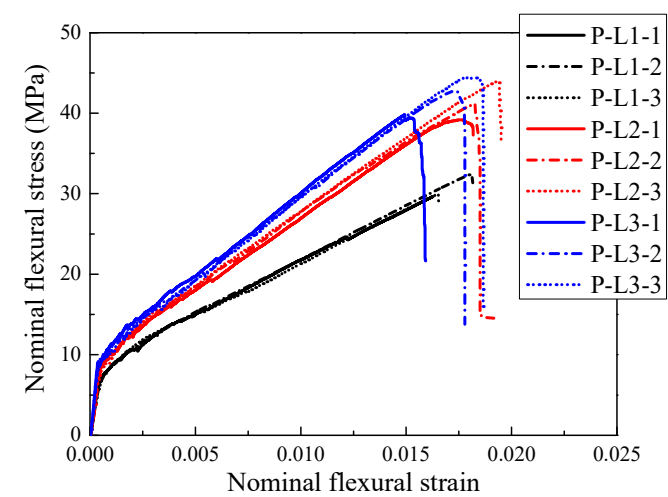

Fig. 6. Flexural behaviour of printed TRC specimens.

Direct comparisons of the cast and printed TRC specimens are shown in Fig. 7. It is encouraging to observe that the $3 \mathrm{D}$ printed TRC specimens have very similar flexural responses to the cast equivalents in terms of nominal flexural strength, flexural stiffness and post-cracking ductility, indicating that the printing process does not result in significant detrimental effects compared to the conventionally cast equivalent. The 
test results of printed TRC specimens show high consistency (Fig. 7 and Table 4), which might be due to the precise digitally controlled printing process.

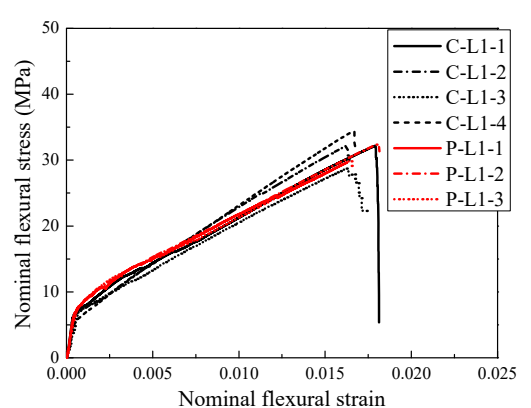

(a) One layer of textile

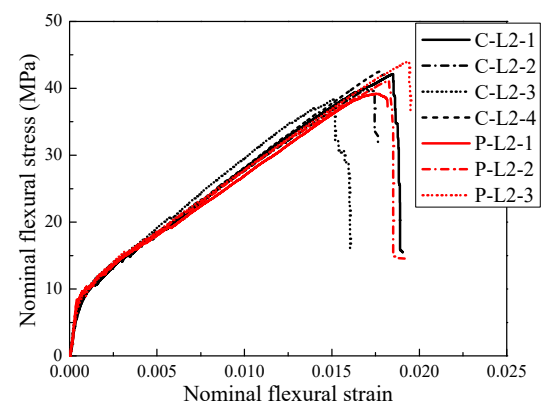

(b) Two layers of textiles

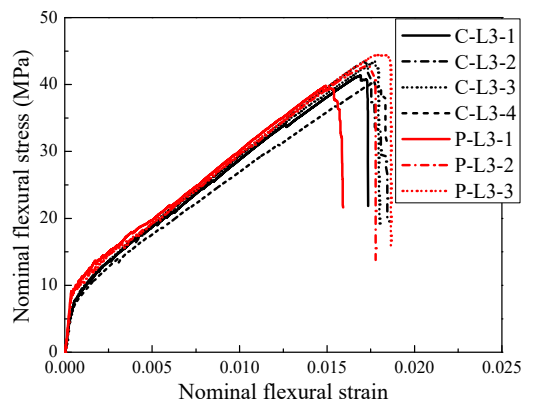

(c) Three layers of textiles

Fig. 7. Comparison of the cast and printed TRC specimens

\section{Conclusions}

This study aimed to investigate the use of AR-glass textile as the reinforcement of 3D printed concrete. To validate this strategy, cast and printed thin-shelled beam specimens were prepared with one to three layers of textiles. The specimens were tested in flexure under three-point loading. Based on the test results, the following conclusions can be made:

1. The textile reinforced concrete (TRC) specimens exhibit satisfactory flexural behaviours under three-point loading with significant strength and post-cracking ductility. The textile location affects the flexural behaviour of cast and printed TRC specimens: the bottom layer of textile provides the highest tensile resistance, followed by the middle and top layers of textiles.

2. $3 \mathrm{D}$ printed TRC specimens have very similar responses to the equivalent cast TRC specimens in terms of nominal flexural strength, flexural stiffness and postcracking ductility, indicating that there aren't any detrimental effects related to the printing process. 
3. The flexural behaviours of printed TRC specimens exhibit lower scatter than the cast TRC specimens, which is probably due to the precise digitally controlled printing process.

Based on these preliminary test results, future research should be conducted on the theoretical modelling of the flexural behaviour of printed TRC specimens as well as manufacture of textile reinforcement for more complex 3D printed concrete structures. Moreover, research on the automated textile placement method should be a priority.

\section{References}

1. Buswell R.A., de Silva W.L., Jones S., Dirrenberger J: 3D printing using concrete extrusion: A roadmap for research. Cement and Concrete Research 112, 37-49 (2018).

2. Wangler T., Roussel N., Bos F.P., Salet T.A. et al: Digital concrete: a review. Cement and Concrete Research 123, 105780 (2019).

3. Asprone D., Menna C., Bos F.P., Salet T.A.M. et al: Rethinking reinforcement for digital fabrication with concrete. Cement and Concrete Research 112, 111-21 (2018).

4. De Schutter G., Lesage K., Mechtcherine V., Nerella V.N. et al: Vision of 3D printing with concrete - technical, economic and environmental potentials. Cement and Concrete Research 112, 25-36 (2018).

5. Costanzi C.B., Ahmed Z., Schipper H., Bos F. et al: 3D Printing concrete on temporary surfaces: The design and fabrication of a concrete shell structure. Automation in Construction 94, 395-404 (2018).

6. Hawkins W., Orr J., Ibell T., Shepherd P: An analytical failure envelope for the design of textile reinforced concrete shells. Structures 15, 56-65 (2018).

7. Hegger J., Voss S: Investigations on the bearing behaviour and application potential of textile reinforced concrete. Engineering Structures 30, 2050-6 (2008).

8. Le T.T., Austin S.A., Lim S., Buswell R.A. et al: Hardened properties of high-performance printing concrete. Cement and Concrete Research 42, 558-66 (2012).

9. British Standards Institution: BS EN 12390-3:2009 Testing hardened concrete - Compressive strength of test specimens, Milton Keynes, UK (2009). 